\title{
Dormancy in metacommunities
}

2

4

\author{
Nathan I. Wisnoski ${ }^{1 *}$, Mathew A. Leibold ${ }^{2}$, Jay T. Lennon ${ }^{1 *}$ \\ ${ }^{1}$ Department of Biology, Indiana University, Bloomington, Indiana, USA \\ ${ }^{2}$ Department of Biology, University of Florida, Gainesville, Florida, USA
}

6

ORCID: Wisnoski, orcid.org/0000-0002-2929-5231

ORCID: Lennon, orcid.org/0000-0003-3126-6111

8

* Correspondence: wisnoski@indiana.edu and lennonj@indiana.edu

10

Keywords: metacommunity, dormancy, dispersal, coexistence, community monopolization

12

Date: 15 February 2019

14 


\begin{abstract}
16

Although metacommunity ecology has improved our understanding of how dispersal affects community structure and dynamics across spatial scales, it has yet to adequately account

18 for dormancy. Dormancy is a reversible state of reduced metabolic activity that enables temporal dispersal within the metacommunity. Dormancy is also a metacommunity-level process because

20 it can covary with spatial dispersal and affect diversity across spatial scales. We develop a framework to integrate dispersal and dormancy, focusing on the covariation they exhibit, to

22 predict how dormancy modifies the importance of species interactions, dispersal, and historical contingencies in metacommunities. We examine case studies of microcrustaceans in ephemeral

24 ponds, where dormancy is integral to metacommunity dynamics. We analyze traits of bromeliaddwelling invertebrates and identify constraints on dispersal and dormancy strategies. Using

26 simulations, we demonstrate that dormancy can alter classic metacommunity patterns of diversity in ways that depend on dispersal-dormancy covariation and spatiotemporal environmental

28 variability. We propose that dormancy may also facilitate evolution-mediated priority effects if locally adapted seed banks prevent colonization by more dispersal-limited species. We present

30 theoretically and empirically testable predictions for other possible ecological and evolutionary implications of dormancy in metacommunities, some of which may fundamentally alter our

32 understanding of metacommunity ecology.
\end{abstract}




\section{INTRODUCTION}

Metacommunity ecology provides a framework for understanding how processes on

36 multiple spatial scales influence the assembly, structure, and dynamics of communities (Leibold et al. 2004; Holyoak et al. 2005; Leibold and Chase 2018). At the local scale, niche selection

38 (due to abiotic constraints and species interactions) and demographic stochasticity regulate community structure (Chesson 2000a; Adler et al. 2007; Gravel et al. 2011; Vellend 2016). At

40 the regional scale, spatial heterogeneity and dispersal control the feedbacks that arise among communities, while the diversity of species and their degree of niche differentiation reflect the

42 biogeographical history of the regional species pool (Mittelbach and Schemske 2015; Vellend 2016). Thus far, the primary focus of metacommunity ecology has been on dispersal in relation

44 to local processes, such as niche selection (e.g., "species sorting" and "mass effects" models, Cadotte 2006; Grainger and Gilbert 2016; Soininen 2016), stochasticity (e.g., "neutral” models,

46 Hubbell 2001), or competitive hierarchies (e.g., "patch dynamics" models, Tilman 1994).

However, the maturation of metacommunity ecology has demonstrated the need to move beyond

48 idealized models like these and instead focus on a broader metacommunity state space defined by continuous gradients of dispersal, niche selection, stochasticity, and historical biogeography

50 (Vellend 2016; Brown et al. 2017; Leibold and Chase 2018). There is also a growing need to incorporate additional ecological factors to explain discrepancies between theoretical predictions

52 and patterns found in nature.

While metacommunity ecology has overwhelmingly focused on spatial dispersal, many

54 species can also engage in dormancy, a reversible state of reduced metabolic activity that allows individuals to disperse through time via storage in a 'seed bank' of long-lived, inactive

56 propagules (De Stasio 1990; Hairston and Kearns 2002). Dormancy is of particular relevance for metacommunity ecology because (1) it can buffer against temporarily harsh environments that 
58 could lead to local extinctions (i.e., dormancy weakens the strength of local niche selection) (Lennon and Jones 2011); (2) it can covary with dispersal (Buoro and Carlson 2014); and (3) it

60 has implications for the eco-evolutionary dynamics that influence species distributions across space and time (De Meester et al. 2016). For example, spatial and temporal patterns of diversity

62 in metacommunities, such as colonization-extinction dynamics in a landscape, are typically explained on the basis of spatial dispersal and niche selection in response to environmental

64 variability (e.g., disturbance and recolonization). However, similar patterns may not only be influenced by dormancy (Mahaut et al. 2018), but may fundamentally depend on it (Box 1).

Despite its potential importance for local- and regional-scale processes, dormancy has yet to be adequately incorporated into metacommunity ecology (Leibold and Norberg 2004; Holt et al. 2005; Alexander et al. 2012). Here, we explore the role of dormancy in metacommunities from both ecological and evolutionary perspectives. We first review the evolutionary ecology of

70 dispersal and dormancy as life-history strategies for coping with variable environments and emphasize that these traits are not necessarily independent (Buoro and Carlson 2014). We then

72 consider the ecological and evolutionary implications of dormancy for community assembly, metacommunity dynamics, and species distributions in metacommunities. We examine case

74 studies where dormancy underlies metacommunity dynamics, we create a simulation model showing that dormancy affects diversity across spatial scales, and we analyze the dispersal and

76 dormancy strategies of a large collection of taxa to show how metacommunity ecologists might incorporate dormancy into their research. We conclude with future directions to further integrate 78 dormancy into metacommunity ecology. 
Dispersal is the net movement of organisms away from their natal habitat. It minimizes

84 the risk of local extinction, reduces kin competition, accommodates foraging strategies, and allows populations to track environmental conditions across the landscape (for recent reviews,

86 see Ronce 2007; Cheptou et al. 2017; Cote et al. 2017). Dispersal also promotes species coexistence at the regional scale if it increases intraspecific competition relative to interspecific 88 competition (Amarasekare 2003). For example, competition-colonization trade-offs allow inferior resource competitors to coexist in the metacommunity if they are better at colonizing 90 recently disturbed habitats (Tilman 1994). Dispersal-mediated coexistence can be further enhanced by spatial heterogeneity. Spatial heterogeneity allows different species to be favored in

92 different patches of the metacommunity, a crucial element of the spatial storage effect (Chesson 2000b; Shoemaker and Melbourne 2016). Spatial heterogeneity also provides the environmental

94 context that determines whether dispersal is limiting, sufficient, or too high relative to the strength of local niche selection, which regulates the degree to which species distributions can be 96 explained by environmental variation alone (Leibold and Chase 2018). Although it offers many benefits, dispersal is costly; it requires time, energy, and risk, which suggests possible trade-offs

98 with other life-history traits (Bonte et al. 2012; Stevens et al. 2012), such as dormancy.

Dormancy is a reversible state of reduced metabolic activity that has independently

100 evolved many times across the tree of life (Guppy and Withers 1999; Evans and Dennehy 2005; Lennon and Jones 2011; Rafferty and Reina 2012). We focus on forms of dormancy that result in 102 the production of metabolically inactive propagules that accumulate into a 'seed bank'. The seed bank buffers against harsh environmental conditions and may contribute to the long-term

104 maintenance of taxonomic, phylogenetic, and functional diversity (Warner and Chesson 1985; Hairston and Kearns 2002; Lennon and Jones 2011). If the environment favors different species 
106 at different times, dormancy can promote species coexistence via the temporal storage effect (Warner and Chesson 1985), such that species partition temporal niches due to the preservation 108 of overlapping generations in the seed bank (Chesson 2000a). Dormancy may also affect the relative strength of deterministic versus stochastic eco-evolutionary processes by altering 110 population sizes (Ellstrand and Elam 1993; Orrock and Watling 2010; Gilbert and Levine 2017; Shoemaker and Lennon 2018). In unpredictable environments, a fraction of the population could 112 remain dormant even when environmental conditions are favorable (i.e., bet hedging; Evans and Dennehy 2005; Childs et al. 2010; Starrfelt and Kokko 2012). As with dispersal, dormancy has

114 costs, including delayed reproduction, losses due to burial (Hairston et al. 1995) or predation (Janzen 1971; Horst and Venable 2018), and the energetic costs of producing and maintaining 116 dormant life stages (Finkelstein et al. 2008; Lennon and Jones 2011).

As two of the most common strategies for coping with environmental variability,

118 dispersal and dormancy are similar in many ways (Den Boer 1968; Bohonak and Jenkins 2003). Successful spatial and temporal dispersal consists of three phases: (1) emigration, or initiation of 120 dormancy, (2) movement, or survival through unfavorable environments, and (3) colonization, or reactivation from dormancy (Buoro and Carlson 2014). We operationally define the dispersal

122 and dormancy capacities of a species based on their ability to successfully complete these three phases of spatial or temporal dispersal. Species with greater capacities for dormancy may

124 accumulate into a persistent seed bank that spans greater temporal scales (i.e., a large temporal species pool), while species that engage in short-term dormancy could occupy a transient seed

126 bank. The collection of dispersal and dormancy traits among species in the metacommunity can then influence the types of metacommunity dynamics that arise (Fig. 1). Thus, relative to the 128 spatiotemporal scales of environmental variability, some species can disperse further in time, 
while other species can disperse further in space, enabling assessment in a metacommunity

130 context.

Despite their similarities, dispersal and dormancy can have different implications for

132 metacommunity ecology depending on environmental variability (Levin et al. 1984; Venable and Brown 1988; Cohen and Levin 1991). For example, neither dispersal nor dormancy will be

134 successful in environmentally static landscapes. Species with better dispersal capabilities should be favored in spatiotemporally variable landscapes with lower spatial synchrony, such that

136 populations can track favorable habitats over time in the metacommunity (McPeek and Holt 1992). In contrast, dormancy should be favored in temporally fluctuating landscapes with high

138 spatial synchrony (i.e., many patches experience similar conditions, reducing the effectiveness of dispersal) or when favorable habitats are spatially isolated (for review, see Buoro and Carlson

140 2014). Dispersal and dormancy may also differ in their ability to maintain diversity in disturbed landscapes (McPeek and Kalisz 1998). Temporal dispersers in the seed bank may be better

142 protected against short-term, regional-scale disturbances that eliminate spatial refuges (e.g., hurricanes). Alternatively, spatial dispersers may be better protected against local-scale

144 disturbances that outlast the range of temporal dispersal, allowing species to persist in other patches of the metacommunity. Currently, dispersal and spatial heterogeneity dominate

146 contemporary understanding of metacommunity dynamics, but dormancy and temporal variability are analogous factors that can interactively influence diversity across space and time 148 (Fig. 1).

The relationship between dispersal and dormancy is a key component of the life history 152 of a species (Buoro and Carlson 2014; Rubio de Casas et al. 2015). It is often assumed that 
dispersal and dormancy negatively covary, consistent with the view that there is a trade-off

154 between these life-history strategies, such that species with high capacities for dormancy have low dispersal rates, and vice versa. This trade-off is thought to exist because dormancy reduces

156 local fitness variability, and thus, the need to disperse (Levin et al. 1984; Cohen and Levin 1987, 1991; Venable and Brown 1988). For example, a synthesis of British seed plants indicated that 158 species with better dispersal abilities had lower dormancy capabilities (Rees 1993). Allocation constraints could also prohibit maximal investment in traits that enhance both dormancy and 160 dispersal, setting up the trade-off (Ehrlén and van Groenendael 1998). Additional empirical support for negative dispersal-dormancy covariation exists (Ehrlén and van Groenendael 1998;

162 Bégin and Roff 2002), but it is not universal (Siewert and Tielbörger 2010; Buoro and Carlson 2014), suggesting that other factors may mask this trade-off.

164 There is also evidence that dispersal and dormancy can exhibit different relationships. Positive dispersal-dormancy covariation, where species with greater capacities for dormancy 166 also disperse greater distances across space, is another possibility. Positive covariation could arise under a number of conditions, such as when environmental favorability changes rapidly or

168 unpredictably in both space and time (Venable and Brown 1988; Cohen and Levin 1991; Snyder 2006; Buoro and Carlson 2014). Positive dispersal-dormancy covariation may also be due to 170 genetic linkage or pleiotropy (Peiman and Robinson 2017), such as when traits that increase capacities for dormancy interact with traits that enhance dispersal abilities, or vice versa.

172 Therefore, positive selection for dispersal or dormancy indirectly selects for the other strategy as well. For example, zooplankton that produce more durable dormant propagules make longer

174 lasting contributions to local seed banks, but they also disperse greater distances by better surviving ingestion by waterfowl, important dispersal vectors of freshwater invertebrates

176 (Figuerola and Green 2002; Viana et al. 2016). Regardless of the mechanism behind dispersal- 
dormancy covariation, estimating dispersal and dormancy capabilities is key for predicting how 178 dormancy influences metacommunities (Box 3).

\section{THE METACOMMUNITY ECOLOGY OF DORMANCY}

To demonstrate how covariation between dormancy and dispersal influences

184 metacommunities, we created a simulation model (Box 2, Supplementary Material). Our modeling demonstrates that dormancy affects the distribution of local $(\alpha)$, among-site $(\beta)$, and

186 regional $(\gamma)$ diversity along a dispersal gradient (Fig. B2.1). In addition, our models reveal that the effects of dormancy on metacommunity diversity depend on the degree of spatiotemporal variability in the environment, species' capacities for spatial and temporal dispersal, and the type of dispersal-dormancy covariation in the metacommunity. In this section, we expand on our

190 modeling results by discussing the potential mechanisms by which dormancy can affect three important aspects of metacommunity ecology: community assembly, community dynamics, and

192 species distributions.

194 [Insert Box 2 here.]

Seed banks can introduce temporal variability in the spatial scale of community

198 assembly. This arises in part because the importance of the seed bank is greatest during the early stages of community assembly (Roxburgh et al. 2004). For example, seed banks allow weeds to rapidly colonize ephemeral crop habitats until niche selection favors more competitive species 
(Ryan et al. 2010; Mahaut et al. 2018). Similarly, prior to the arrival of spatial dispersers,

202 microcrustacean seed banks in temporary wetlands can drive rapid community assembly following extended periods of desiccation (Vanschoenwinkel et al. 2010; Kneitel 2018; Box 1).

204 However, even with a local seed bank, dispersal can still play a role in the early stages of assembly. Across a 40-year successional gradient in a subalpine birch forest, dispersal played a

206 consistently strong role in community assembly, but the importance of dormancy declined with increasing time since disturbance (Vandvik and Goldberg 2006). As a result, recently or

208 frequently disturbed plant communities tend to have the highest compositional similarity to the seed bank, but this is not always the case (Hopfensperger 2007; Saatkamp et al. 2014). Thus,

210 transitions from local, dormancy-driven assembly to regional, dispersal-driven assembly appear to be common, but the implications for metacommunity dynamics could depend on the frequency

212 and spatiotemporal pattern of disturbance.

Dispersal-dormancy covariation is important for community assembly because it could

214 determine which species colonize a site from the seed bank versus from elsewhere in the metacommunity. For example, good dispersers may also be abundant in the regional seed bank

216 (positive covariation), and the combination of spatial and temporal dispersal by these species may contribute to the homogenization of diversity among sites (Box 2). Alternatively, local seed

218 banks may contain different species than the active or dormant species found in other patches (as might be expected with negative covariation), so that spatial and temporal dispersal events reflect

220 different species pools. Consequently, the spatial isolation and disturbance frequency of a site may be important controls on community assembly because they determine whether community

222 assembly proceeds primarily from spatial or temporal dispersal. For example, spatial isolation plays a major role in the assembly of benthic macroinvertebrates in intermittent streams in the 
224 U.S. Southwest because sites near perennial headwaters are colonized via spatial dispersal while sites near intermittent headwaters rely on dormancy (Bogan and Lytle 2007; Bogan et al. 2015).

\section{Community Dynamics}

Dormancy can interact with local community dynamics in ways that may be decoupled from dispersal rates, depending on dispersal-dormancy covariation. As a result, dormancy could

230 help explain empirical deviations from classical metacommunity predictions based on dispersal rates, niche differences, and spatial heterogeneity alone. For example, sufficient dispersal rates

232 are thought to be necessary for species to persist in disturbance prone landscapes (Hanski and Gilpin 1997), but seed banks can maintain local colonization-extinction dynamics in the absence

234 of dispersal from the metacommunity if environmental conditions fluctuate on time scales that are shorter than the range of temporal dispersal by propagules in the seed bank (Mergeay et al.

236 2007, 2011; Ventura et al. 2014). The spatial variation in community dynamics generated by temporal dispersal could appear indistinguishable from that generated by spatial dispersal, but it

238 would be due to purely local processes or as a result of combined spatial and temporal dispersal (Mahaut et al. 2018).

Even with strong temporal environmental tracking, reactivation from dormancy does not necessarily lead to successful reestablishment of a population. Reestablishment from the seed

242 bank may fail due to niche preemption by similar species that have already emerged from the seed bank, introducing historical contingencies that may have stochastic elements (Fukami 2015;

244 Schwentner and Richter 2015). Species could also emerge from the seed bank under unfavorable environmental conditions (e.g., due to stochastic reactivation or bet hedging), maintaining sink

246 populations in the community via temporal dispersal (a temporal mass effect, Shmida and Ellner 1984; Rajaniemi et al. 2006; Mahaut et al. 2018). Other species might miss favorable 
248 opportunities for growth due to misinterpreted environmental cues or failures during the temporal dispersal process (i.e., they are 'dormancy limited') (Donohue et al. 2010), which may

250 allow competitively inferior species to occupy habitats that superior competitors fail to recolonize. Spatial variation in the stochastic or historically contingent outcomes of temporal

252 dispersal would create mismatches between environmental conditions and community composition that current metacommunity theory might attribute to unmeasured spatial

254 heterogeneity or dispersal. It is possible that these mismatches due to temporal dispersal could even occur in the absence of spatial heterogeneity or source-sink relationships.

\section{Species Distributions} modifying colonization rates and patch invasibility (Gillespie et al. 2012; Gioria et al. 2012) as

260 illustrated, for example, by the spread of exotic species by the transport of dormant propagules (e.g., in the ballast water of ships, Briski et al. 2011). Dormancy could allow colonizers that

262 arrive during unfavorable environmental conditions to persist until conditions improve, increasing the probability of successful establishment (Gioria et al. 2012). For example, the high

264 dispersal rate and persistent seed bank of Acacia dealbata may contribute to its invasiveness and expanding spatial distribution (Gibson et al. 2011). In a recent study, the seed bank density of $A$.

266 dealbata reached more than 60,000 seeds $\mathrm{m}^{-2}$ in invaded plots compared to only 9 seeds $\mathrm{m}^{-2}$ in uninvaded plots (Passos et al. 2017). Invasion by Acacia has also been shown to reduce the

268 density of native seeds in the seed bank, which further reinforces aboveground losses in species diversity (Gioria et al. 2014; Gioria and Pyšek 2016). The large seed banks of invasive species

270 may even buffer the community against subsequent invasion due to rapid colonization. Thus, when coupled with high dispersal ability, dormancy may facilitate spatial homogenization not 
272 only by reducing and replacing local diversity within a site, but also by facilitating the rapid spread of species throughout a metacommunity (Box 2).

274 Dormancy can also affect the spatial distribution of species via temporal mass effects.

Even if species have the ability to persist in a seed bank via dormancy, environmental conditions

276 may not always favor establishment. For example, dormancy and dispersal maintain thermophilic bacteria in the cold Arctic Ocean, an environment where they are metabolically

278 disfavored (Hubert et al. 2009). The ability of microorganisms to persist in unfavorable environments via dormancy could also help explain deviations in their spatial and temporal

280 patterns of diversity from those of macro-organisms (Lennon and Jones 2011; Shade et al. 2018). In another example from an alpine lake, local seed banks enabled the recovery of a cladoceran 282 species (Daphnia middendorffiana), which can grow asexually, but not a copepod species (Hesperodiaptomus shoshone), which relies on sexual reproduction (Sarnelle and Knapp 2004).

284 For the copepod, finding a mate after emerging from the seed bank is rare, causing an Allee effect (Sarnelle and Knapp 2004; Kramer et al. 2008). Although temporal mass effects may 286 explain the occasional presence of a copepod in this lake, their lack of recovery also suggests they could be dispersal limited relative to nearby lakes. Thus, dormancy can influence the spatial 288 distributions of species in a metacommunity, often in unanticipated ways, due to spatial and temporal processes.

\section{EVOLVING METACOMMUNITIES WITH DORMANCY}

Dormant seed banks could further influence community assembly and metacommunity dynamics through evolutionary processes by altering the arrival of species and rates of local

294 adaptation (Leibold et al. 2005; Urban and Skelly 2006; Loeuille and Leibold 2008; Urban et al. 2008; De Meester et al. 2016). The community monopolization hypothesis posits that local 
296 adaptation by early arriving species can create priority effects that prevent the establishment of later arriving species and alter regional patterns of diversity (Urban et al. 2008; Urban and De

298 Meester 2009; Leibold et al. 2019). Community monopolization is likely to occur when early colonizers can rapidly adapt to local conditions (e.g., due to short generation times) and when

300 colonization events are rare and infrequent (e.g., due to spatial isolation and dispersal limitation) (De Meester et al. 2016; Vanoverbeke et al. 2016). But dormant seed banks provide another 302 mechanism of colonization that could modify the importance of community monopolization for metacommunity dynamics.

Dormancy can regulate community monopolization by shortening or lengthening the time between the arrival of maladapted colonists and the arrival of pre-adapted species that would drive them extinct. For example, because seed banks facilitate recolonization they could lengthen the time for early colonists to locally adapt and monopolize the community, especially when 308 spatial isolation contributes to dispersal limitation. However, even with high immigration seed banks can be locally adapted (De Meester et al. 2002; Falahati-Anbaran et al. 2014; Ventura et 310 al. 2014). Seed banks also store genetic diversity that provides a source of gene flow from the past (Hairston and Kearns 2002; Vitalis et al. 2004; Lundemo et al. 2009; Rubio de Casas et al. 312 2015). Maladaptive gene flow from the seed bank can inhibit monopolization by slowing the response to directional selection (Templeton and Levin 1979; Hairston and De Stasio 1988;

314 Shoemaker and Lennon 2018; Tellier 2019), a process we call the 'dormancy load'. Alternatively, under fluctuating selection, seed banks can facilitate local adaptation by allowing 316 different genotypes to be favored at different times (i.e., a genetic storage effect, Ellner and Hairston 1994; Hedrick 1995; Nunney 2002; Vitalis et al. 2004). Thus, high dormancy load can 318 slow local adaptation and allow a preadapted species to interrupt community monopolization. However, if early colonizers build up genetically diverse seed banks in fluctuating patches, they 
320 are more likely to monopolize them even when environmental fluctuations occur (Loeuille and Leibold 2008).

Although we have reviewed some of the possibilities above, the role of the seed bank in community monopolization will be highly context dependent. This is because the outcome of

324 community assembly depends on the genetic variation of populations in the seed bank relative to spatial colonizers, the covariation between dormancy and dispersal, colonization order, and

326 environmental variability in relation to the emergence of genotypes and species from the seed bank.

\section{FUTURE DIRECTIONS}

We have shown that dormancy can have many consequences for metacommunity ecology and evolution, but there remains much more to learn about how dormancy and seed banks

332 influence the distribution of species through space and time. In this section, we briefly highlight three research needs that would yield greater insight into the possible roles of dormancy in 334 metacommunities.

Modeling Studies

The difficulty of empirically measuring dispersal has led to an increased reliance on

338 models for generating and testing new hypotheses in metacommunity ecology. Likewise, challenges associated with measuring dormancy also pose significant hurdles. Modeling studies

340 (e.g., analytical or simulation-based) can be used explore the vast parameter space of dispersal and dormancy beyond what can be accurately measured in most organisms. A key challenge will

342 be to understand how dormancy might alter the predictions of current metacommunity theory under different collections of species (with varying dispersal-dormancy covariation), under 
344 different patterns of environmental variability (e.g., spatial and temporal autocorrelation or disturbance), and under different starting conditions or assembly histories. Even under simplified conditions, our models suggest that dormancy affects a fundamental property of metacommunity ecology: the distribution of diversity across spatial scales (Box 2). However, more complex models would yield much deeper insight into the nuanced roles of dormancy in metacommunities. For example, models could extensively explore how dormancy affects

350 metacommunity structure through local, regional, historical, and evolutionary mechanisms that are difficult or impossible to measure empirically.

\section{Empirical Studies}

From the empirical perspective, it is unclear whether different taxonomic groups have characteristic patterns of dispersal-dormancy covariation, and whether dispersal-dormancy 356 covariation is influenced by other traits, such as body size or dispersal mode. We have shown that invertebrate species commonly found in bromeliad plants display a wide range of dispersal

358 and dormancy capacities (Box 3), but generalizations are difficult without extensive trait measurements across diverse taxonomic groups and ecosystems. Accurate measurements of

360 dispersal and dormancy are notoriously difficult to acquire, but estimates of these traits for cooccurring species at the metacommunity scale are invaluable. For example, identifying species

362 differences in dispersal kernels (Sullivan et al. 2018) and dormant propagule survivorship (e.g., Frisch 2002) would be especially informative for predicting how species distributions in

364 metacommunities relate to spatiotemporal variation in the environment. Trait data could then be used to test whether predictions derived from different dispersal and dormancy strategies

366 correspond with patterns of diversity observed in the field. For example, multivariate statistics can quantify the degree to which community dynamics are explained by spatial, temporal, 
368 biogeographical, trait, and environmental predictors (e.g., Leibold et al. 2010; Legendre and Legendre 2012; Peres-Neto et al. 2012, 2017; Dray et al. 2014). Furthermore, manipulative experiments in the field or in mesocosms may shed further light on the roles of spatial and temporal dispersal.

[Insert Box 3 here.]

\section{Adding Trophic Complexity}

Trophic interactions and consumer movement can influence spatial and temporal patterns

376 of diversity, which may explain discrepancies between empirical studies and competition-based metacommunity theory (Haegeman and Loreau 2014; Grainger and Gilbert 2016; Leibold and

378 Chase 2018; Guzman et al. 2019). Dormant propagules often differ in their vulnerability to predators and pathogens (Hulme 1998; Klobutcher et al. 2006; Waterkeyn et al. 2011; Horst and

380 Venable 2018), which could affect their survival in the seed bank and temporal dispersal capabilities. For example, while high predator dispersal can eliminate spatial refuges for

382 vulnerable prey, predator-resistant dormant stages could introduce temporal refuges that stabilize prey populations in the metacommunity. In some systems, dormancy may even be an adaptation

384 to host-parasite interactions (Verin and Tellier 2018), suggesting dormancy may be a trait of interest in evolving metacommunities that include predation. However, dormant propagules at a

386 high risk of consumption (e.g., Waterkeyn et al. 2011) could increase predator abundances and destabilize prey populations (of several species) at the metacommunity scale via inter-patch 388 apparent competition. In addition, predators might also have the ability to enter a dormant stage. Predator seed banks could prevent prey species from occupying some patches by driving prey 390 extinct upon reactivation (Livingston et al. 2017). These colonization-extinction dynamics resemble, but fundamentally differ from, those driven by dispersal (Huffaker 1958; Hilborn 
392 1975). Our understanding of dormancy in metacommunities would benefit greatly from: (1) manipulative experiments that measure how the presence or absence of predators, seed banks,

394 and environmental heterogeneity contribute to metacommunity dynamics, and (2) modeling approaches that extensively explore how more complex food webs (e.g., including predators,

396 omnivores, mutualists, pathogens, etc.) may regulate the relative importance of dormancy and dispersal for metacommunity structure, diversity, and stability.

\section{CONCLUSIONS}

Dormancy is a common life-history trait can influence metacommunity structure, dynamics, and diversity. Our simulations suggest that the effects of dormancy on

402 metacommunity diversity depend on dispersal-dormancy covariation and environmental variability, proposing a tighter integration between spatial and temporal dimensions in

404 metacommunity ecology. Building on our models, we propose that the dispersal and dormancy capacities of species in the metacommunity modify the relative importance of local (e.g., species

406 interactions, abiotic constraints), historical (e.g., priority effects, temporal mass effects) and regional (e.g., dispersal and spatial heterogeneity) factors underlying metacommunity structure.

408 The range of potential metacommunity dynamics expands even further when we incorporate evolution (e.g., via the community monopolization hypothesis), but the outcomes are likely to be

410 highly context dependent. Dormancy can facilitate community monopolization through rapid recolonization from the seed bank and by buffering against maladaptive gene flow, but it may

412 also inhibit monopolization if dormancy load prevents local adaptation. Using case studies from natural metacommunities, simulation models, and an analysis of dispersal-dormancy covariation,

414 we have demonstrated some of the implications of dormancy for metacommunities and have suggested ways to more fully incorporate dormancy into metacommunity research. While the 
416 context-dependent role of dispersal in metacommunities is now increasingly clear, our synthesis reveals that dormancy may play a similarly important role that may strongly interact with that of 418 dispersal in ways that remain to be elucidated. 


\section{BOXES}

420 Box 1: Evidence from nature: microcrustacean metacommunities

Many species are capable of entering dormant stages that can influence their distributions

422 across time and space. Microcrustaceans, such as cladocerans, copepods, and fairy shrimp, have a broad range of dispersal (Jenkins and Buikema 1998; Cáceres and Soluk 2002;

424 Vanschoenwinkel et al. 2009) and dormancy capabilities (Brendonck et al. 2016; Ellegaard and Ribeiro 2018). For example, the production of dormant ephippia in response to food limitation,

426 crowding, or seasonality (Fig. B1.1A), allows species of Daphnia to coexist at the local scale via the temporal storage effect (Cáceres 1997). Daphnia have high capacities for temporal dispersal

428 because their ephippia can remain viable for over a century (Cáceres 1998). Dormancy also has direct implications for zooplankton metacommunity dynamics because it enables dispersal

430 between isolated aquatic habitats by wind, water, or animal vectors (Bohonak and Jenkins 2003; Havel and Shurin 2004). Traits related to dormant propagules, such as buoyancy, can influence

432 dispersal-dormancy covariation (Pinceel et al. 2013). For example, floating ephippia are readily dispersed, but sinking propagules remain in the local seed bank (Ślusarczyk and Pietrzak 2008).

434 In contrast to Daphnia, cladocera in the genus Chydorus attach their ephippia to littoral macrophytes (Fryer 1972; Frey 1986), restricting their dispersal. Thus, we can use species

436 differences in dispersal and dormancy to make predictions for metacommunity dynamics.

The influence of seed banks on metacommunity diversity has been well-documented

438 through the study of crustaceans in temporary aquatic habitats including wetlands and rock pools. In temporary rock pools (Fig. B1.1B), seed banks maintain permanent resident species by

440 allowing them to endure periods of desiccation, but they also facilitate wind-blown dispersal to other pools when the pools are dry (Brendonck and Riddoch 1999; Jocque et al. 2010;

442 Brendonck et al. 2016). The importance of dormancy for among-pool dispersal demonstrates 
how local cues to enter dormancy can have metacommunity-wide implications. In this system,

444 the early successional niche is available exclusively to dormant organisms, consistent with the prediction that seed banks affect diversity most strongly following disturbances. The seed bank

446 allows early successional species to persist in the metacommunity even though they are often driven locally extinct by competitors and predators that colonize later via aerial dispersal

448 (Vanschoenwinkel et al. 2010). Additional evidence from microcrustaceans in California vernal pools $(\mathrm{n}=787)$ suggests dormancy affects regional patterns of diversity (Kneitel 2016, 2018).

450 Among generalists in this system, passive dispersers with the ability to enter dormancy (ostracods, cladocerans, and copepods) have much higher site occupancy ( $>50 \%)$ than active

452 dispersers that lack dormancy (Kneitel 2018). Together, these examples show how dormancy can influence metacommunity structure and dynamics in spatiotemporally variable landscapes. 


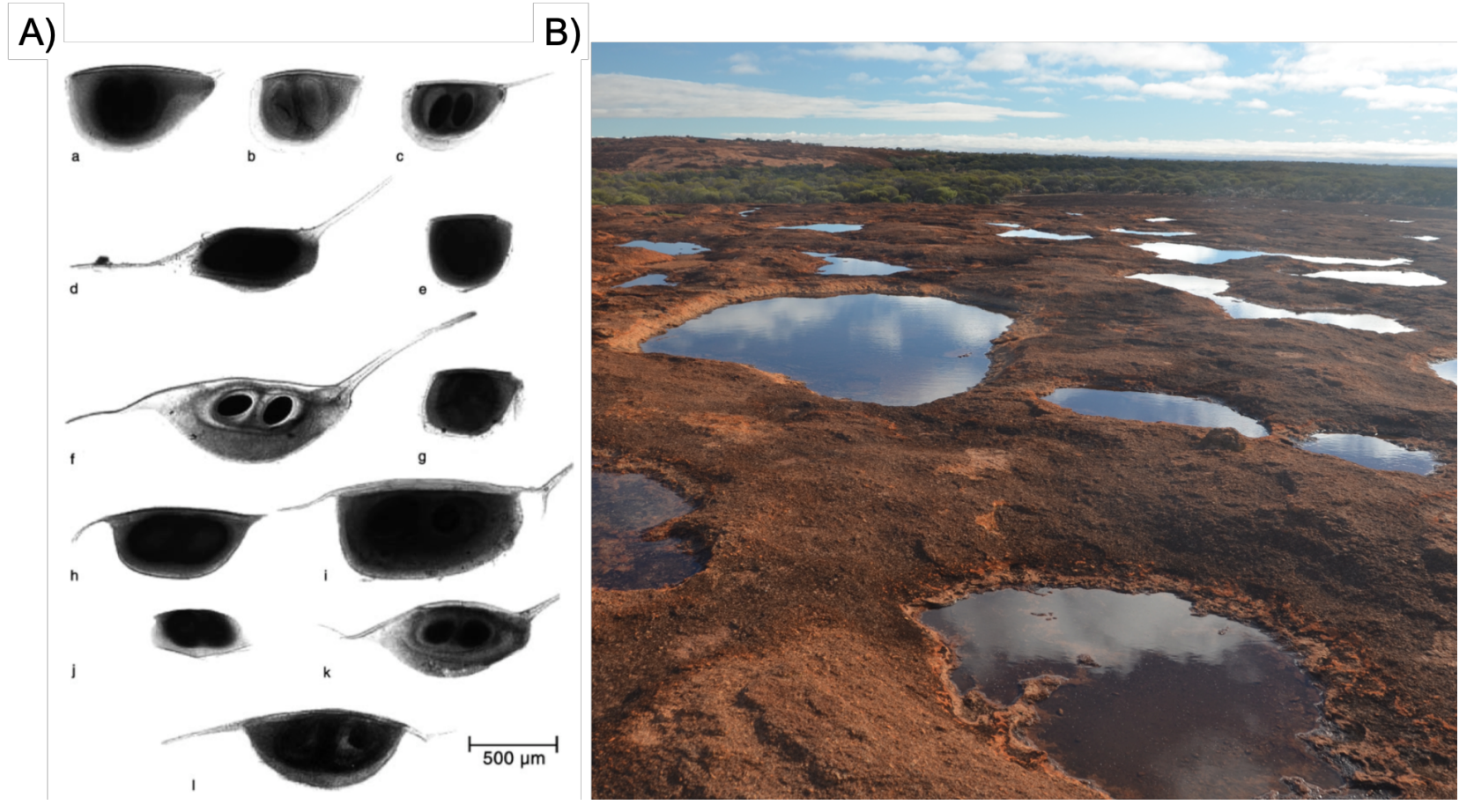

Figure B1.1 - Microcrustacean dormancy is common in variable environments. (A) The

458 diversity of Daphnia ephippia from a survey of 41 water bodies in Kenya, where seed bank diversity was more than twice the diversity of active communities (image from Mergeay et al.

460 2005). The high diversity lurking in the seed bank indicates the potential for dormancy to influence metacommunity trajectories in different ways depending on which species colonize the 462 active community, the order in which they emerge from the seed bank, and the favorability of the environment they experience upon reactivation. (B) Temporary rock pools contain species that

464 typically have some form of dormancy to endure extended periods of desiccation and to facilitate recolonization from the seed bank upon rewetting. Image credit: B. Vanschoenwinkel (source:

466 https://insularecology.files.wordpress.com/2013/09/dsc 06291.jpg). 


\section{Box 2: Modeling dormancy in metacommunities}

We explored the effects of dormancy in metacommunities using simulation models (see Supplement 1). A fundamental aspect of metacommunity ecology is that species diversity varies

472 across spatial scales and can be partitioned into diversity at the local scale ( $\alpha$-diversity), diversity among sites ( $\beta$-diversity), and diversity at the regional scale ( $\gamma$-diversity). The partitioning of

474 diversity across scales is also known to depend on the rate of dispersal in a metacommunity (Mouquet and Loreau 2003; Grainger and Gilbert 2016). Because we propose that dormancy has

476 implications for the maintenance of diversity at the local scale, and because dormancy likely covaries with dispersal, we examined the effects of dormancy on the diversity-dispersal 478 relationship.

We modified a general metacommunity model (Shoemaker and Melbourne 2016) to 480 include transitions in and out of a dormant seed bank. Briefly, population dynamics are modeled in discrete time according to the Beverton-Holt model of population growth, dispersal is global,

482 the metacommunity is spatially heterogeneous, dormancy occurs at a constant rate in and out of the seed bank, and dormant propagules undergo geometric decay. Because dormancy and

484 dispersal are likely to be found in disturbed environments, we modeled random disturbance as the removal of all active individuals in a patch, following a Bernoulli distribution for each patch 486 independently at a specified extinction rate (Shoemaker and Melbourne 2016). More details about the model and its variations can be found in the supplemental information (S1). We

488 partitioned diversity multiplicatively using a Hill numbers approach (order $=1$, corresponding to the Shannon index of diversity) and diversity units are species equivalents (Jost 2007).

$490 \quad$ Our models indicate that dormancy has substantial effects on the partitioning of diversity across scales in ways that depend on the rate of dispersal, dispersal-dormancy covariation, and 492 environmental variability. When dispersal-dormancy covariation is negative (i.e., dormancy 
comes with a dispersal cost), dormancy maintains diversity when dispersal is limiting relative to

494 disturbance rate because temporal dispersal from the seed bank allows populations to recolonize patches (Fig. B2.1). However, dormancy cannot mitigate the homogenizing effects of high

496 dispersal rates. When there is positive dispersal-dormancy covariation, dormancy and dispersal interactively affect the dispersal rate that maximizes metacommunity diversity: dormancy

498 maintains peak diversity at lower dispersal rates, but magnifies the effects of homogenization; without dormancy, more dispersal is needed for species to keep up with the disturbance regime

500 of the landscape (Fig. B2.1). Even in static landscapes without disturbance, where dormancy is not expected to be evolutionarily favored, seed banks can maintain higher $\alpha$-diversity at lower

502 dispersal rates and amplify the homogenizing effects of dispersal under positive dispersaldormancy covariation (Fig. S1.1).

Although by no means comprehensive, our simulations illustrate three important features of biodiversity in metacommunities: 1) dormancy alters the distribution of diversity across 506 spatial scales, 2) these effects can depend strongly on the nature of spatiotemporal environmental variation, and 3) these effects interact with dispersal in ways that depend on the nature of 508 dispersal-dormancy covariation. 


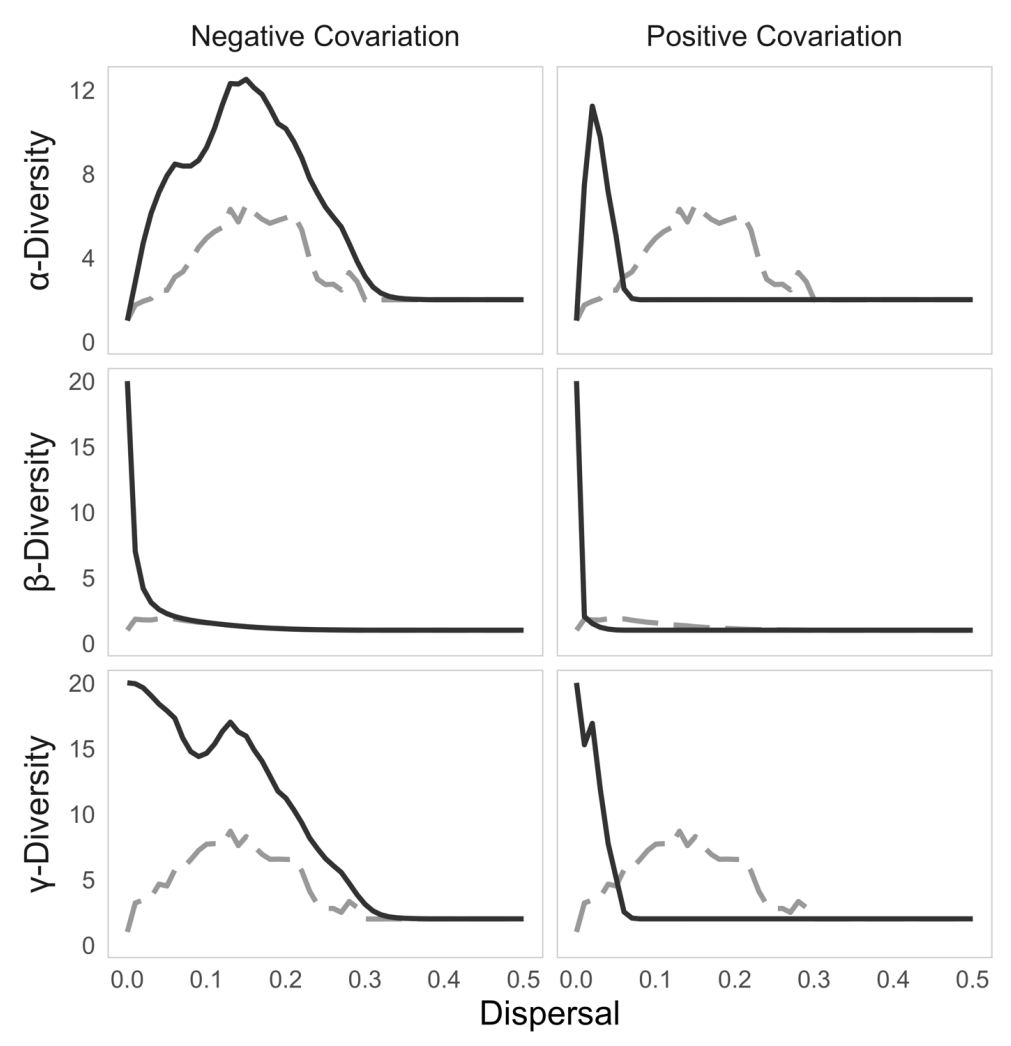

512 Figure B2.1 - Dispersal-diversity relationships with (dark solid line) and without (dashed light line) dormancy in an environment subject to local disturbance, commonly associated with

514 dispersal and dormancy strategies. Dormancy maintains higher $\alpha$ - and $\gamma$-diversity under both negative and positive dispersal-dormancy covariation. With negative covariation (i.e., a trade-

516 off), dormancy maintains higher $\alpha$ - and $\gamma$-diversity, especially at lower dispersal rates, and maintains $\beta$-diversity under dispersal limitation (i.e., at very low dispersal rates). However,

518 dormancy cannot protect against homogenization (regional diversity decreases with increasing dispersal, regardless of dormancy). With positive dispersal-dormancy covariation, dormancy

520 lowers the dispersal rate that maximizes $\alpha$-, $\beta$-, and $\gamma$-diversity, increases maximum $\alpha$ - and $\gamma$ diversity, and also increases the homogenizing effects of dispersal. The metacommunity with

522 dormancy is homogenized (e.g., one species dominates) at dispersal rates that were potentially limiting in the absence of dormancy. 


\section{Box 3: How to study dispersal-dormancy covariation in metacommunities}

Incorporating dispersal-dormancy covariation into empirical and modeling studies is an important next step for fully integrating spatial and temporal dimensions into metacommunity ecology. Recently, a suite of twelve functional traits were measured for 852 invertebrate taxa that represent the species pool of the aquatic inhabitants of tropical tank bromeliads from Mexico to Argentina (Céréghino 2018; Céréghino et al. 2018). A full analysis showed that observed trait variation in the bromeliad invertebrates filled less than $25 \%$ of the potential trait space,

532 suggesting trait covariation constrains the niche space of these taxa (Céréghino et al. 2018). Bromeliad invertebrate communities are model systems for studying metacommunities because

534 of their patchy distribution in forests, openness to colonization, and experimental tractability (Lecraw et al. 2014; Petermann et al. 2015).

Using the subset of taxa with trait measurements for both dispersal and dormancy $(\mathrm{n}=$ 609 taxa), we sought to identify groups of taxa with similar dispersal and dormancy strategies 538 that may co-occur in a metacommunity. We used a fuzzy clustering algorithm ( $c$-means) to group taxa with similar dispersal and dormancy trait values (Kaufman and Rousseeuw 1990;

540 Maechler et al. 2018). We clustered taxa into three groups $(\mathrm{k}=3$, average silhouette width $=$ 0.68), and used principal components analysis (PCA) on the rank-ordered trait data to visualize

542 the location of these groups in reduced dimensions and to generate continuous descriptions of the dispersal and dormancy strategies among these taxa (Podani 2005; Borcard et al. 2018;

544 Céréghino et al. 2018). We plot vectors showing the PCA loadings to describe the trait differences underlying cluster membership.

546 We observed wide variation among taxa in their dispersal and dormancy strategies (Fig. B3.1). Notably, the first principal component describes a trade-off between passive and active 548 dispersal $\left(\rho=-0.76, p_{\text {Holm-adjusted }}<10^{-9}\right)$. The second principal component describes the 
dormancy capacity of each taxon. As with other trait dimensions (Céréghino et al. 2018), we

550 found that taxa span, but do not fill, the dispersal-dormancy trait space, suggesting that trait covariation partially constrains dispersal and dormancy strategies. Many taxa exhibited patterns

552 consistent with a trade-off between dispersal and dormancy: Cluster 1 (lower-right quadrant) includes strong passive dispersers with low dormancy capacities, Cluster 2 (upper-left) includes

554 weak dispersers with high dormancy capacities, and Cluster 3 (lower-left) includes active dispersers with poor dormancy capacities (Fig B3.1). However, some taxa exhibit high capacities

556 for both dispersal and dormancy (upper-right, upper-left), hence similar membership in the three clusters. More detailed information about the taxa in each cluster is available in the supplemental 558 material.

Our analysis suggests that some species may be better at spatial dispersal and other

560 species are likely better at temporal dispersal, but that dispersal-dormancy covariation could restrict the life-history strategies these taxa could employ. We may be able to predict their

562 distributions in a metacommunity with knowledge of the regional species pool, the dispersal and dormancy traits of those species, and spatiotemporal variation in environmental variables by

564 using the principal components as quantitative predictors in multivariate statistical models (e.g., the fourth-corner approach, Dray and Legendre 2008; Peres-Neto et al. 2017). 


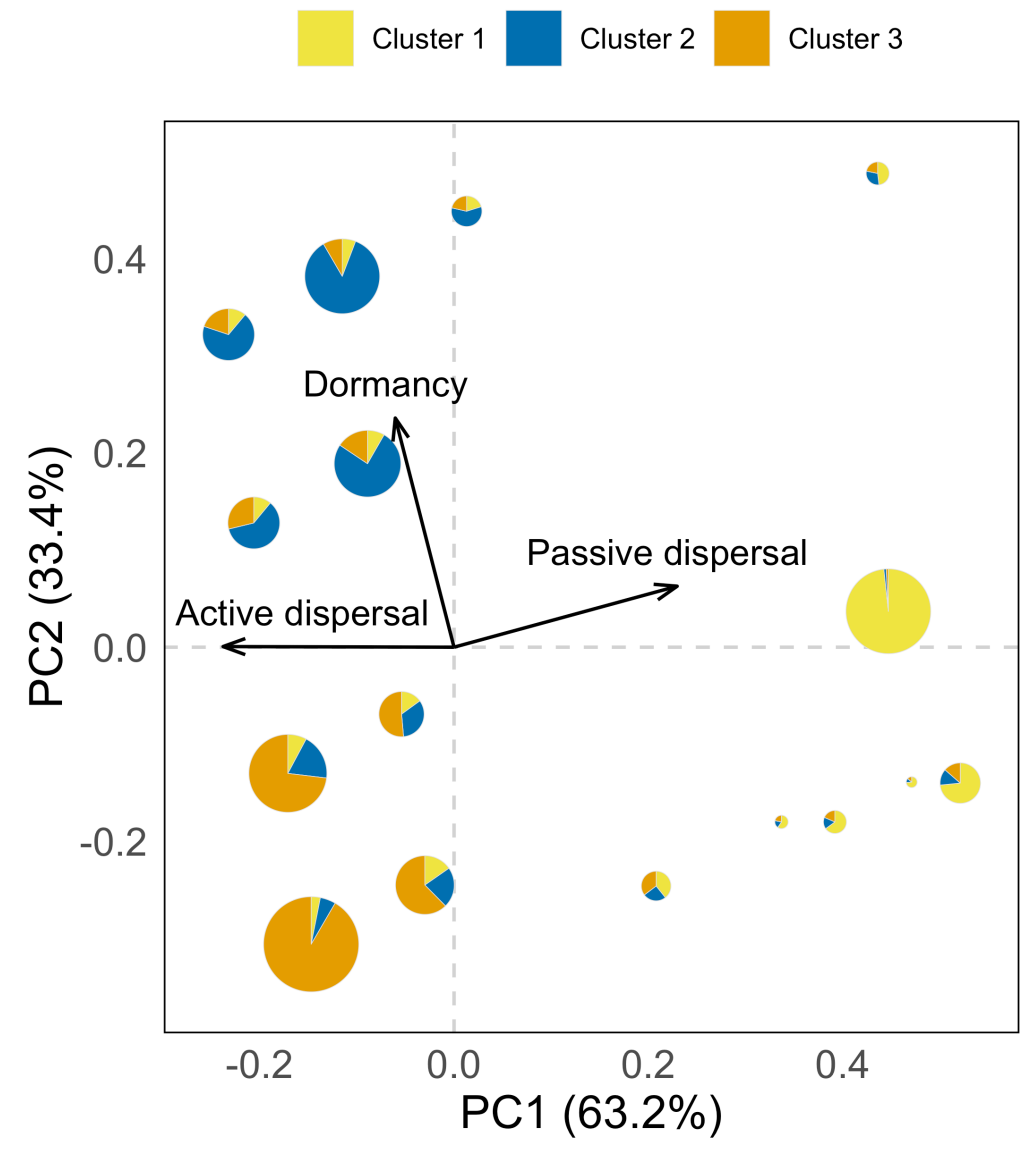

570 Figure B3.1 - A range of dispersal and dormancy strategies were observed among aquatic invertebrate taxa found in tropical bromeliads across South America $(n=609)$ (Céréghino 2018).

572 The relative size of each wedge in each pie represents the proportional membership of taxa in each of the three clusters. Vectors describe the location of clusters in dispersal-dormancy trait-

574 space. Total area of the pie is proportional to the number of taxa observed with each trait combination. 


\section{TABLES}

580 Table 1 - Modifications to metacommunity theory with the inclusion of dormancy.

\section{Concept}

Colonization-extinction

dynamics

Turnover in $\gamma$-diversity

Diversity-dispersal

relationship

\section{Without dormancy}

Colonization results from

spatial dispersal alone.

\section{With dormancy}

Colonization can occur from within a patch by propagules from the past.

The loss or gain of a species Species may disappear and at the regional scale indicates reappear in the future as a that a species either went result of long-term storage in regionally extinct or the the seed bank. metacommunity was invaded.

Homogenization (i.e., the Spatial and temporal dispersal erosion of $\beta$-diversity) results interact to homogenize the from high rates of metacommunity over space contemporary dispersal. and time, decoupling homogenization from contemporary dispersal rates.
Community monopolization
Following a disturbance,
Following a disturbance, good dispersers are more
dormant organisms may 


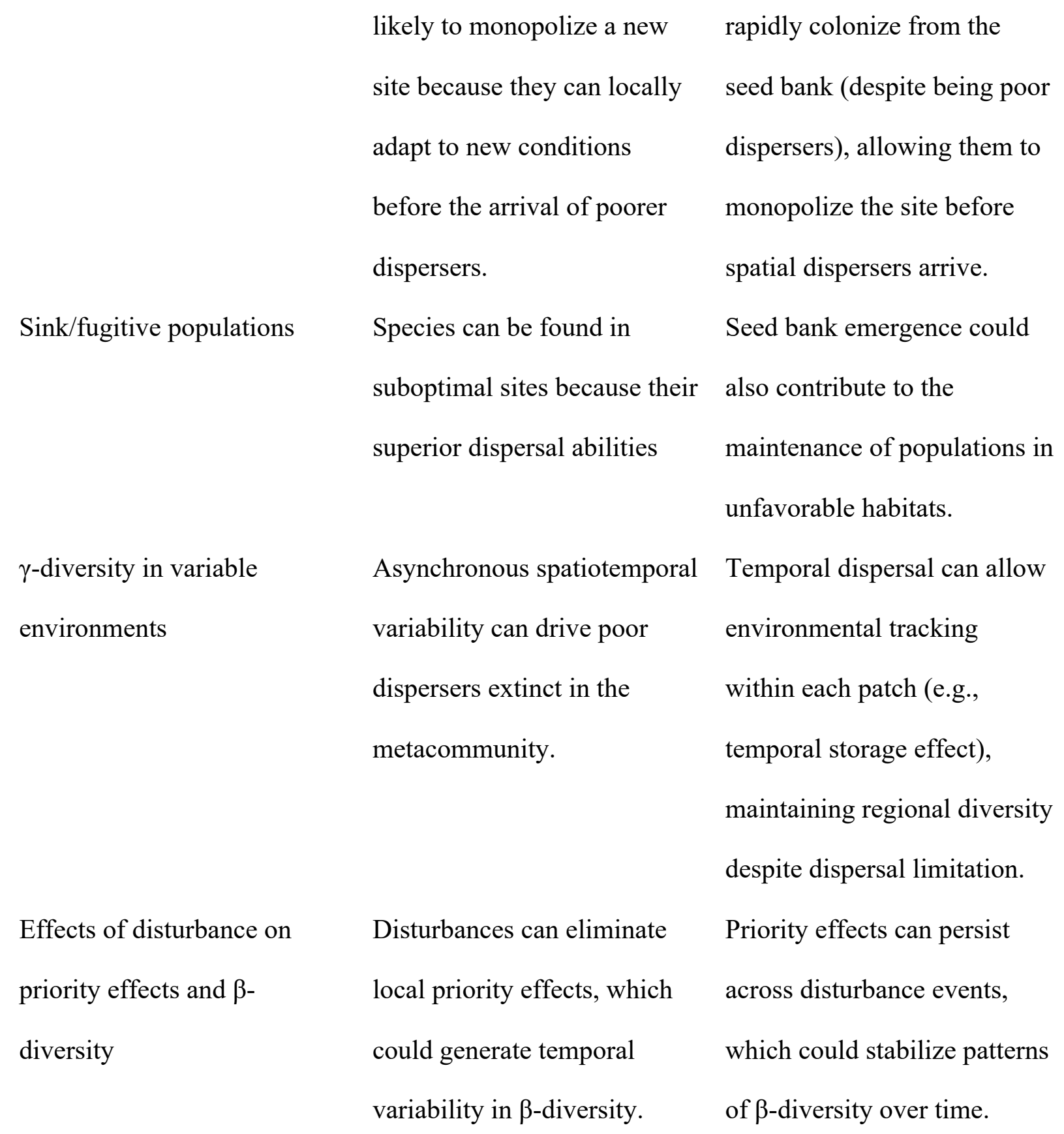


582 Table 2 - Testable predictions about dormancy in metacommunity ecology

\section{Predictions for dormancy in metacommunities}

Large scale, spatially autocorrelated disturbances will decrease $\beta$-diversity and increase the abundance of temporal dispersers; small scale, spatially asynchronous disturbances will increase $\beta$-diversity and favor spatial and temporal dispersers.

Spatially isolated patches will be more affected by priority effects during community assembly due to a greater role of temporal than spatial dispersal.

Species with high capacities for dormancy and dispersal will occupy more sites in the metacommunity and have larger species ranges than species that exhibit a trade-off between dormancy and dispersal, or lack dormancy altogether.

In directionally changing environments, dormancy will inhibit community monopolization by imposing high dormancy load; in fluctuating environments, dormancy will facilitate monopolization via genetic storage effects.

Species Area Relationships (SARs) will have higher intercepts and steeper slopes (with negative dispersal-dormancy covariation) or shallower slopes (with positive dispersaldormancy covariation) than SARs without dormancy.

Species with high capacities for dormancy are likely to be dispersal limited under negative dispersal-dormancy covariation, and at risk of spatial mass effects under positive dispersal-dormancy covariation, creating mismatches between species composition and environmental conditions.

In trophic metacommunities, when dormant propagules are vulnerable to predation, dormancy may lead to apparent competition, but when dormant propagules are resistant to predation, dormancy could provide a refuge that maintains prey diversity. 
In metacommunities with frequent local disturbances, but high spatial isolation between patches, dormancy may be more important for community dynamics and species distributions than dispersal when species exhibit a trade-off between dispersal and dormancy.

In spatiotemporally fluctuating environments, when local fluctuations occur on longer time scales than the temporal dispersal range of species in the metacommunity, dormancy is less important than dispersal for maintaining diversity under negative dispersaldormancy covariation (because individuals are lost to the seed bank); under positive dispersal-dormancy covariation, dormancy could help maintain diversity at low spatial dispersal rates. 


\section{FIGURES}

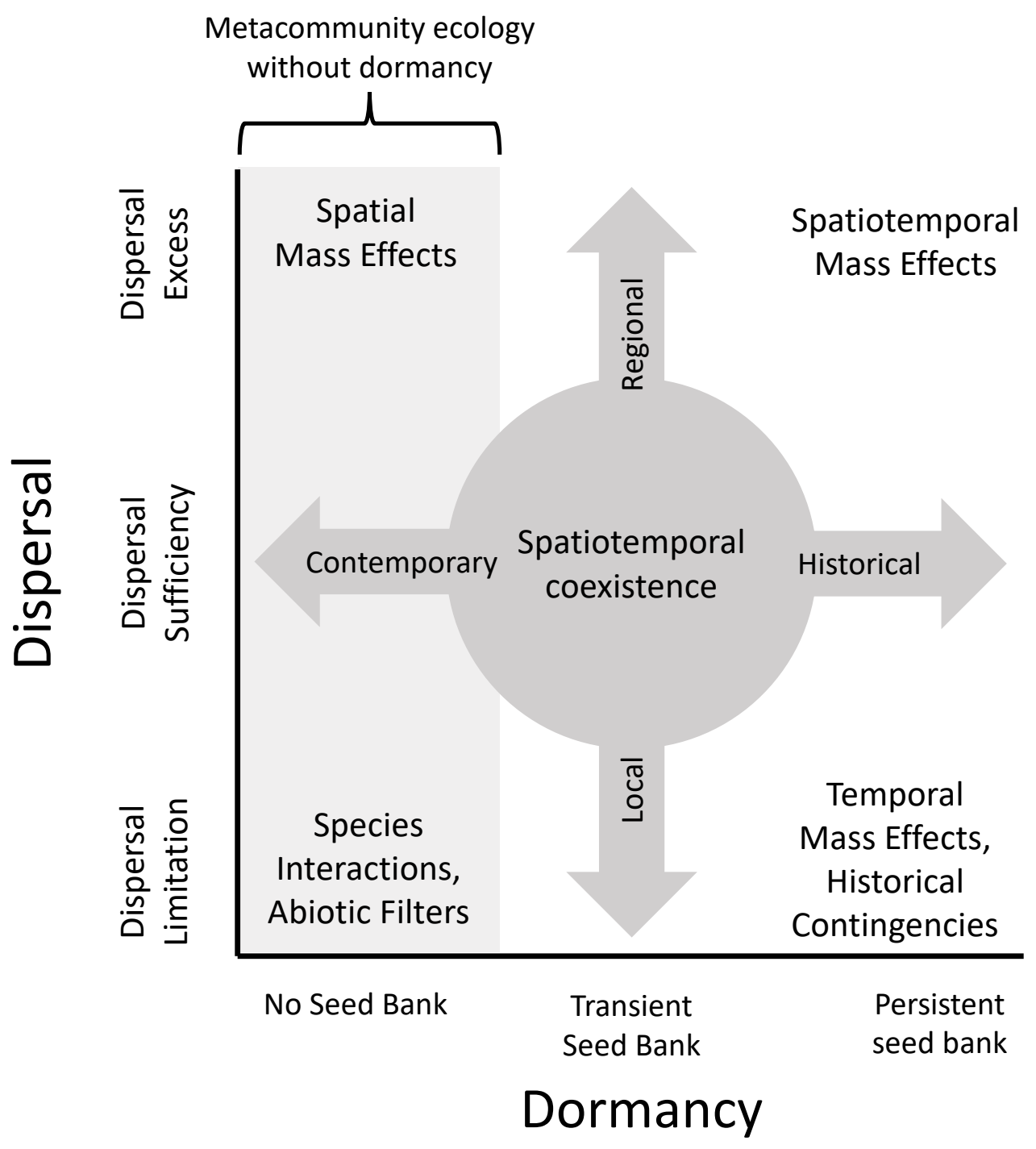

588 Figure 1 - Dormancy expands the possible metacommunity dynamics to include historical factors due to the presence of a seed bank. As dispersal increases (along the vertical axis),

590 regional factors become increasingly important for local community structure and dynamics. As dormancy increases (along the horizontal axis), propagules in the seed bank have greater

592 temporal dispersal capacities and potential to influence future ecological and evolutionary dynamics. In the absence of a seed bank, traditional metacommunity theory applies, leading to 
594 outcomes predicted when dispersal is limiting, sufficient, or in excess of the strength of local niche selection. Towards the lower right corner (high temporal dispersal, low spatial dispersal),

596 historical contingencies and dispersal limitation may dominate community assembly, causing high spatial turnover relative to what would be expected based on spatial heterogeneity and 598 dispersal alone. Increasing dispersal is likely to mitigate the historical controls from the seed bank, potentially leading to spatial and temporal homogenization, as our models indicate under 600 positive dispersal-dormancy covariation. 


\section{REFERENCES}

604 Adler, P. B., J. HilleRisLambers, and J. M. Levine. 2007. A niche for neutrality. Ecology Letters 10:95-104.

606 Alexander, H. M., B. L. Foster, F. Ballantyne, C. D. Collins, J. Antonovics, and R. D. Holt. 2012. Metapopulations and metacommunities: combining spatial and temporal

608 perspectives in plant ecology: Plant metapopulations and metacommunities. Journal of Ecology 100:88-103.

610 Amarasekare, P. 2003. Competitive coexistence in spatially structured environments: a synthesis. Ecology Letters 6:1109-1122.

612 Bégin, M., and D. A. Roff. 2002. The common quantitative genetic basis of wing morphology and diapause occurrence in the cricket Gryllus veletis. Heredity 89:473-479.

614 Bogan, M. T., K. S. Boersma, and D. A. Lytle. 2015. Resistance and resilience of invertebrate communities to seasonal and supraseasonal drought in arid-land headwater streams.

$616 \quad$ Freshwater Biology 60:2547-2558.

Bogan, M. T., and D. A. Lytle. 2007. Seasonal flow variation allows "time-sharing” by disparate aquatic insect communities in montane desert streams. Freshwater Biology 52:290-304.

Bohonak, A. J., and D. G. Jenkins. 2003. Ecological and evolutionary significance of dispersal by freshwater invertebrates. Ecology Letters 6:783-796.

Bonte, D., H. Van Dyck, J. M. Bullock, A. Coulon, M. Delgado, M. Gibbs, V. Lehouck, et al. 2012. Costs of dispersal. Biological Reviews 87:290-312.

Borcard, D., F. Gillet, and P. Legendre. 2018. Numerical ecology with R (2nd ed.). Springer International Publishing, Cham, Switzerland. 
Brendonck, L., T. Pinceel, and R. Ortells. 2016. Dormancy and dispersal as mediators of zooplankton population and community dynamics along a hydrological disturbance gradient in inland temporary pools. Hydrobiologia 1-22.

628 Brendonck, L., and B. J. Riddoch. 1999. Wind-borne short-range egg dispersal in anostracans (Crustacea: Branchiopoda). Biological Journal of the Linnean Society 67:87-95.

630 Briski, E., S. A. Bailey, and H. J. MacIsaac. 2011. Invertebrates and their dormant eggs transported in ballast sediments of ships arriving to the Canadian coasts and the Laurentian Great Lakes. Limnology and Oceanography 56:1929-1939.

Brown, B. L., E. R. Sokol, J. Skelton, and B. Tornwall. 2017. Making sense of metacommunities: dispelling the mythology of a metacommunity typology. Oecologia 183:643-652.

636 Buoro, M., and S. M. Carlson. 2014. Life-history syndromes: integrating dispersal through space and time. Ecology Letters 17:756-767.

638 Cáceres, C. E. 1997. Temporal variation, dormancy, and coexistence: a field test of the storage effect. Proceedings of the National Academy of Sciences 94:9171-9175.

640 Cáceres, C. E. 1998. Interspecific variation in the abundance, production, and emergence of Daphnia diapausing eggs. Ecology 79:1699-1710.

642 Cáceres, C. E., and D. A. Soluk. 2002. Blowing in the wind: a field test of overland dispersal and colonization by aquatic invertebrates. Oecologia 131:402-408.

644 Cadotte, M. W. 2006. Dispersal and species diversity: a meta-analysis. The American Naturalist 167:913-924.

646 Céréghino, R. 2018. Constraints on the functional trait space of aquatic invertebrates in bromeliads. Knowledge Network for Biocomplexity. doi:10.5063/F1VD6WMF. 
648 Céréghino, R., V. D. Pillar, D. S. Srivastava, P. M. de Omena, A. A. M. MacDonald, I. M. Barberis, B. Corbara, et al. 2018. Constraints on the functional trait space of aquatic $650 \quad$ invertebrates in bromeliads. Functional Ecology 32:2435-2447.

Cheptou, P.-O., A. L. Hargreaves, D. Bonte, and H. Jacquemyn. 2017. Adaptation to fragmentation: evolutionary dynamics driven by human influences. Philosophical Transactions of the Royal Society B: Biological Sciences 372.

654 Chesson, P. 2000a. Mechanisms of maintenance of species diversity. Annual Review of Ecology and Systematics 31:343-366.

$656-2000 \mathrm{~b}$. General theory of competitive coexistence in spatially-varying environments. Theoretical population biology 58:211-37.

658 Childs, D. Z., C. J. E. Metcalf, and M. Rees. 2010. Evolutionary bet-hedging in the real world: empirical evidence and challenges revealed by plants. Proceedings of the Royal Society 660 B: Biological Sciences.

Cohen, D., and S. A. Levin. 1987. The interaction between dispersal and dormancy strategies in varying and heterogeneous environments. Pages 110-122 in E. Teramoto and M. Yumaguti, eds. Mathematical Topics in Population Biology, Morphogenesis and 664 Neurosciences: Proceedings of an International Symposium held in Kyoto, November 10-15, 1985. Springer Berlin Heidelberg, Berlin, Heidelberg.

666 Cohen, D., and S. A. Levin. 1991. Dispersal in patchy environments: the effects of temporal and spatial structure. Theoretical Population Biology 39:63-99.

668 Cote, J., E. Bestion, S. Jacob, J. Travis, D. Legrand, and M. Baguette. 2017. Evolution of dispersal strategies and dispersal syndromes in fragmented landscapes. Ecography 40:5673. 
De Meester, L., A. Gómez, B. Okamura, and K. Schwenk. 2002. The Monopolization

672 Hypothesis and the dispersal-gene flow paradox in aquatic organisms. Acta Oecologica 23:121-135.

674 De Meester, L., J. Vanoverbeke, L. J. Kilsdonk, and M. C. Urban. 2016. Evolving perspectives on monopolization and priority effects. Trends in Ecology \& Evolution 31:136-146.

676 De Stasio, B. T., Jr. 1990. The role of dormancy and emergence patterns in the dynamics of a freshwater zooplankton community. Limnology and Oceanography 35:1079-1090.

678 Den Boer, P. J. 1968. Spreading of risk and stabilization of animal numbers. Acta Biotheoretica 18:165-194.

680 Donohue, K., R. Rubio de Casas, L. Burghardt, K. Kovach, and C. G. Willis. 2010. Germination, postgermination adaptation, and species ecological ranges. Annual Review of Ecology, Evolution, and Systematics 41:293-319.

Dray, S., P. Choler, S. Dolédec, P. R. Peres-Neto, W. Thuiller, S. Pavoine, and C. J. F. ter Braak. 684 2014. Combining the fourth-corner and the RLQ methods for assessing trait responses to environmental variation. Ecology 95:14-21.

686 Dray, S., and P. Legendre. 2008. Testing the species traits-environment relationships: The fourth-corner problem revisited. Ecology 89:3400-3412.

688 Ehrlén, J., and J. M. van Groenendael. 1998. The trade-off between dispersability and longevity an important aspect of plant species diversity. Applied Vegetation Science 1:29-36.

690 Ellegaard, M., and S. Ribeiro. 2018. The long-term persistence of phytoplankton resting stages in aquatic 'seed banks.' Biological Reviews 93:166-183.

692 Ellner, S., and N. G. Hairston Jr. 1994. Role of overlapping generations in maintaining genetic variation in a fluctuating environment. The American Naturalist 143:403-417. 
694 Ellstrand, N. C., and D. R. Elam. 1993. Population genetic consequences of small population size: implications for plant conservation. Annual Review of Ecology and Systematics 24:217-242.

Evans, M. E. K., and J. J. Dennehy. 2005. Germ banking: bet-hedging and variable release from egg and seed dormancy. The Quarterly Review of Biology 80:431-451.

Falahati-Anbaran, M., S. Lundemo, and H. K. Stenøien. 2014. Seed dispersal in time can counteract the effect of gene flow between natural populations of Arabidopsis thaliana. New Phytologist 202:1043-1054.

702 Figuerola, J., and A. J. Green. 2002. Dispersal of aquatic organisms by waterbirds: a review of past research and priorities for future studies. Freshwater Biology 47:483-494.

704 Finkelstein, R., W. Reeves, T. Ariizumi, and C. Steber. 2008. Molecular aspects of seed dormancy. Annual Review of Plant Biology 59:387-415.

706 Frey, D. G. 1986. The non-cosmopolitanism of chydorid Cladocera: implications for biogeography and evolution. Pages $237-256$ in R. H. Gore and K. L. Heck, eds. Crustacean Biogeography. A.A. Balkema, Rotterdam.

Frisch, D. 2002. Dormancy, dispersal and the survival of cyclopoid copepods (Cyclopoida, Copepoda) in a lowland floodplain. Freshwater Biology 47:1269-1281.

Fryer, G. 1972. Observations on the ephippia of certain macrothricid cladocerans. Zoological Journal of the Linnean Society 51:79-96.

Fukami, T. 2015. Historical contingency in community assembly: integrating niches, species pools, and priority effects. Annual Review of Ecology, Evolution, and Systematics 46:123. 
716 Gibson, M. R., D. M. Richardson, E. Marchante, H. Marchante, J. G. Rodger, G. N. Stone, M. Byrne, et al. 2011. Reproductive biology of Australian acacias: Important mediator of invasiveness? Diversity and Distributions 17:911-933.

Gilbert, B., and J. M. Levine. 2017. Ecological drift and the distribution of species diversity. Proceedings of the Royal Society B: Biological Sciences 284.

Gillespie, R. G., B. G. Baldwin, J. M. Waters, C. I. Fraser, R. Nikula, and G. K. Roderick. 2012. Long-distance dispersal: A framework for hypothesis testing. Trends in Ecology and Evolution 27:47-55.

724 Gioria, M., V. Jarošík, and P. Pyšek. 2014. Impact of invasions by alien plants on soil seed bank communities: Emerging patterns. Perspectives in Plant Ecology, Evolution and Systematics 16:132-142.

Gioria, M., and P. Pyšek. 2016. The legacy of plant invasions: changes in the soil seed bank of invaded plant communities. BioScience 66:40-53.

Gioria, M., P. Pyšek, and L. Moravcová. 2012. Soil seed banks in plant invasions: promoting species invasiveness and long-term impact on plant community dynamics. Preslia 84:327-350.

732 Grainger, T. N., and B. Gilbert. 2016. Dispersal and diversity in experimental metacommunities: linking theory and practice. Oikos 125:1213-1223.

734 Gravel, D., F. Guichard, and M. E. Hochberg. 2011. Species coexistence in a variable world. Ecology Letters 14:828-839.

736 Guppy, M., and P. Withers. 1999. Metabolic depression in animals: physiological perspectives and biochemical generalizations. Biological Reviews 74:1-40. 
738 Guzman, L. M., R. M. Germain, C. Forbes, S. Straus, M. I. O’Connor, D. Gravel, D. S. Srivastava, et al. 2019. Towards a multi-trophic extension of metacommunity ecology. $740 \quad$ Ecology Letters 22:19-33.

Haegeman, B., and M. Loreau. 2014. General relationships between consumer dispersal, resource dispersal and metacommunity diversity. Ecology Letters 17:175-184.

Hairston, N. G., Jr., and B. T. De Stasio Jr. 1988. Rate of evolution slowed by a dormant propagule pool. Nature 336:239-242.

Hairston, N. G., Jr., and C. M. Kearns. 2002. Temporal dispersal: ecological and evolutionary aspects of zooplankton egg banks and the role of sediment mixing. Integrative and Comparative Biology 42:481-491.

748 Hairston, N. G., Jr., R. A. Van Brunt, C. M. Kearns, and D. R. Engstrom. 1995. Age and survivorship of diapausing eggs in a sediment egg bank. Ecology 76:1706-1711.

750 Hanski, I. A., and M. E. Gilpin, eds. 1997. Metapopulation biology: ecology, genetics, and evolution. Academic Press, San Diego, CA.

752 Havel, J. E., and J. B. Shurin. 2004. Mechanisms, effects, and scales of dispersal in freshwater zooplankton. Limnology and Oceanography 49:1229-1238.

754 Hedrick, P. W. 1995. Genetic polymorphism in a temporally varying environment: effects of delayed germination or diapause. Heredity 75:164-170.

756 Hilborn, R. 1975. The effect of spatial heterogeneity on the persistence of predator-prey interactions. Theoretical Population Biology 8:346-355.

758 Holt, R. D., M. Holyoak, and M. A. Leibold. 2005. Future directions in metacommunity ecology. Pages 465-489 in M. Holyoak, M. A. Leibold, and R. D. Holt, eds. Metacommunities:

760 Spatial Dynamics and Ecological Communities. The University of Chicago Press, Chicago. 
762 Holyoak, M., M. A. Leibold, and R. D. Holt, eds. 2005. Metacommunities: spatial dynamics and ecological communities. University of Chicago Press, Chicago, IL.

764 Hopfensperger, K. N. 2007. A review of similarity between seed bank and standing vegetation across ecosystems. Oikos 116:1438-1448.

766 Horst, J. L., and D. L. Venable. 2018. Frequency-dependent seed predation by rodents on Sonoran Desert winter annual plants. Ecology 99:196-203.

768 Hubbell, S. P. 2001. The unified neutral theory of biodiversity and biogeography. Princeton University Press, Princeton, NJ.

770 Hubert, C., A. Loy, M. Nickel, C. Arnosti, C. Baranyi, V. Brüchert, T. Ferdelman, et al. 2009. A constant flux of diverse thermophilic bacteria into the cold arctic seabed. Science $325: 1541-1544$

Huffaker, C. B. 1958. Experimental studes on predation: dispersion factors and predatory-prey oscillations. Hilgardia 27:343-383.

Hulme, P. E. 1998. Post-dispersal seed predation and seed bank persistence. Seed Science Research 8:513-519.

Janzen, D. H. 1971. Seed predation by animals. Annual Review of Ecology and Systematics $2: 465-492$.

Jenkins, D. G., and A. L. Buikema. 1998. Do similar communities develop in similar sites? A test with zooplankton structure and function. Ecological Monographs 68:421-443.

Jocque, M., B. Vanschoenwinkel, and L. Brendonck. 2010. Freshwater rock pools: a review of habitat characteristics, faunal diversity and conservation value. Freshwater Biology.

Jost, L. 2007. Partitioning diversity into independent alpha and beta components. Ecology $88: 2427-2439$. 
Kaufman, L., and P. J. Rousseeuw. 1990. Finding groups in data: an introduction to cluster analysis. John Wiley \& Sons, Inc, Hoboken, NJ.

Klobutcher, L. A., K. Ragkousi, and P. Setlow. 2006. The Bacillus subtilis spore coat provides "eat resistance" during phagocytic predation by the protozoan Tetrahymena thermophila. Proceedings of the National Academy of Sciences 103:165-170.

790 Kneitel, J. M. 2016. Climate-driven habitat size determines the latitudinal diversity gradient in temporary ponds. Ecology 97:961-968.

792 2018. Occupancy and environmental responses of habitat specialists and generalists depend on dispersal traits. Ecosphere 9:e02143-e02143.

794 Kramer, A. M., O. Sarnelle, and R. A. Knapp. 2008. Allee effect limits colonization success of sexually reproducing zooplankton. Ecology 89:2760-2769.

796 Lecraw, R. M., D. S. Srivastava, and G. Q. Romero. 2014. Metacommunity size influences aquatic community composition in a natural mesocosm landscape. Oikos 123:903-911.

798 Legendre, P., and L. Legendre. 2012. Numerical Ecology (3rd ed.). Elsevier, Amsterdam, Netherlands.

800 Leibold, M. A., and J. M. Chase. 2018. Metacommunity ecology. Princeton University Press, Princeton, NJ.

802 Leibold, M. A., E. P. Economo, and P. Peres-Neto. 2010. Metacommunity phylogenetics: Separating the roles of environmental filters and historical biogeography. Ecology Letters 13:1290-1299.

Leibold, M. A., M. Holyoak, N. Mouquet, P. Amarasekare, J. M. Chase, M. F. Hoopes, R. D. 806 Holt, et al. 2004. The metacommunity concept: a framework for multi-scale community ecology. Ecology Letters 7:601-613. 
808 Leibold, M. A., and J. Norberg. 2004. Biodiversity in metacommunities: Plankton as complex adaptive systems? Limnology and Oceanography 49:1278-1289.

810 Leibold, M. A., M. C. Urban, L. D. Meester, C. A. Klausmeier, and J. Vanoverbeke. 2019. Regional neutrality evolves through local adaptive niche evolution. Proceedings of the National Academy of Sciences 201808615.

Leibold, M., R. D. Holt, and M. Holyoak. 2005. Adaptive and coadaptive dynamics in metacommunities. Pages 439-464 in M. Holyoak, M. A. Leibold, and R. D. Holt, eds. Metacommunities: spatial dynamics and ecological communities. University of Chicago Press, Chicago, IL.

Lennon, J. T., and S. E. Jones. 2011. Microbial seed banks: the ecological and evolutionary implications of dormancy. Nature Reviews Microbiology 9:119-130.

Levin, S. A., D. Cohen, and A. Hastings. 1984. Dispersal strategies in patchy environments. Theoretical Population Biology 26:165-191.

Livingston, G., K. Fukumori, D. B. Provete, M. Kawachi, N. Takamura, and M. A. Leibold. 2017. Predators regulate prey species sorting and spatial distribution in microbial landscapes. Journal of Animal Ecology 86:501-510.

824 Loeuille, N., and M. A. Leibold. 2008. Evolution in metacommunities: on the relative importance of species sorting and monopolization in structuring communities. The American Naturalist 171:788-799.

Lundemo, S., M. Falahati-Anbaran, and H. K. StenøIen. 2009. Seed banks cause elevated 828 generation times and effective population sizes of Arabidopsis thaliana in northern Europe. Molecular Ecology 18:2798-2811.

830 Maechler, M., P. Rousseeuw, A. Struyf, M. Hubert, and K. Hornik. 2018. cluster: cluster analysis basics. 
832 Mahaut, L., G. Fried, and S. Gaba. 2018. Patch dynamics and temporal dispersal partly shape annual plant communities in ephemeral habitat patches. Oikos 127:147-159.

834 McPeek, M. A., and R. D. Holt. 1992. The evolution of dispersal in spatially and temporally varying environments. The American Naturalist 140:1010-1027.

836 McPeek, M. A., and S. Kalisz. 1998. On the joint evolution of dispersal and dormancy in metapopulations. Advances in Limnology 52:33-51.

838 Mergeay, J., L. De Meester, H. Eggermont, and D. Verschuren. 2011. Priority effects and species sorting in a long paleoecological record of repeated community assembly through time. Ecology 92:2267-2275.

Mergeay, J., J. Vanoverbeke, D. Verschuren, and L. D. Meester. 2007. Extinction, recolonization, and dispersal through time in a planktonic crustacean. Ecology 88:30323043.

844 Mergeay, J., D. Verschuren, and L. D. Meester. 2005. Daphnia species diversity in Kenya, and a key to the identification of their ephippia. Hydrobiologia 542:261-274.

846 Mittelbach, G. G., and D. W. Schemske. 2015. Ecological and evolutionary perspectives on community assembly. Trends in Ecology \& Evolution 30:241-247.

848 Mouquet, N., and M. Loreau. 2003. Community patterns in source-sink metacommunities. The American Naturalist 162:544-557.

850 Nunney, L. 2002. The effective size of annual plant populations: the interaction of a seed bank with fluctuating population size in maintaining genetic variation. The American $852 \quad$ Naturalist 160:195-204.

Orrock, J. L., and J. I. Watling. 2010. Local community size mediates ecological drift and 854 competition in metacommunities. Proceedings of the Royal Society B: Biological Sciences 277:2185-2191. 
856 Passos, I., H. Marchante, R. Pinho, and E. Marchante. 2017. What we don't seed: the role of long-lived seed banks as hidden legacies of invasive plants. Plant Ecology 218:13131324.

Peiman, K. S., and B. W. Robinson. 2017. Comparative analyses of phenotypic trait covariation within and among populations. The American Naturalist 190:451-468.

Peres-Neto, P. R., S. Dray, and C. J. F. ter Braak. 2017. Linking trait variation to the environment: critical issues with community-weighted mean correlation resolved by the fourth-corner approach. Ecography 40:806-816.

864 Peres-Neto, P. R., M. A. Leibold, and S. Dray. 2012. Assessing the effects of spatial contingency and environmental filtering on metacommunity phylogenetics. Ecology 93:14-30.

Petermann, J. S., V. F. Farjalla, M. Jocque, P. Kratina, A. A. M. Macdonald, N. A. C. Marino, P. M. De Omena, et al. 2015. Dominant predators mediate the impact of habitat size on trophic structure in bromeliad invertebrate communities. Ecology 96:428-439.

Pinceel, T., B. Vanschoenwinkel, and L. Brendonck. 2013. Flexible dispersal dimorphism in zooplankton resting eggs: an example of repeated phenotypic coin flipping? Biological Journal of the Linnean Society 110:749-756.

872 Podani, J. 2005. Multivariate exploratory analysis of ordinal data in ecology: Pitfalls, problems and solutions. Journal of Vegetation Science 16:497-510.

874 Rafferty, A. R., and R. D. Reina. 2012. Arrested embryonic development: a review of strategies to delay hatching in egg-laying reptiles. Proceedings of the Royal Society B: Biological Sciences 279.

Rajaniemi, T. K., D. E. Goldberg, R. Turkington, and A. R. Dyer. 2006. Quantitative partitioning 878 of regional and local processes shaping regional diversity patterns. Ecology Letters $9: 121-128$. 
Rees, M. 1993. Trade-offs among dispersal strategies in British plants. Nature 366:150-152.

Ronce, O. 2007. How does it feel to be like a rolling stone? Ten questions about dispersal evolution. Annual Review of Ecology, Evolution, and Systematics 38:231-253.

Roxburgh, S. H., K. Shea, and J. B. Wilson. 2004. The intermediate disturbance hypothesis: patch dynamics and mechanisms of species coexistence. Ecology 85:359-371.

Rubio de Casas, R., K. Donohue, D. L. Venable, and P.-O. Cheptou. 2015. Gene-flow through space and time: dispersal, dormancy and adaptation to changing environments. Evolutionary Ecology 29:813-831.

Ryan, M. R., R. G. Smith, S. B. Mirsky, D. A. Mortensen, and R. Seidel. 2010. Management filters and species traits: weed community assembly in long-term organic and conventional systems. Weed Science 58:265-277.

Saatkamp, A., P. Poschlod, and D. L. Venable. 2014. The functional role of soil seed banks in natural communities. Seeds: The Ecology of Regeneration in Plant Communities 263295.

894 Sarnelle, O., and R. A. Knapp. 2004. Zooplankton recovery after fish removal: limitations of the egg bank. Limnology and Oceanography 49:1382-1392.

896 Schwentner, M., and S. Richter. 2015. Stochastic effects associated with resting egg banks lead to genetically differentiated active populations in large branchiopods from temporary water bodies. Hydrobiologia 760:239-253.

Shade, A., R. R. Dunn, S. A. Blowes, P. Keil, B. J. M. Bohannan, M. Herrmann, K. Küsel, et al. 900 2018. Macroecology to unite all life, large and small. Trends in Ecology \& Evolution 33:731-744.

902 Shmida, A., and S. Ellner. 1984. Coexistence of plant species with similar niches. Vegetatio 58:29-55. 
904 Shoemaker, L. G., and B. A. Melbourne. 2016. Linking metacommunity paradigms to spatial coexistence mechanisms. Ecology 97:2436-2446.

906 Shoemaker, W. R., and J. T. Lennon. 2018. Evolution with a seed bank: The population genetic consequences of microbial dormancy. Evolutionary Applications 11:60-75.

908 Siewert, W., and K. Tielbörger. 2010. Dispersal-dormancy relationships in annual plants: putting model predictions to the test. The American Naturalist 176:490-500.

910 Ślusarczyk, M., and B. Pietrzak. 2008. To sink or float: the fate of dormant offspring is determined by maternal behaviour in Daphnia. Freshwater Biology 53:569-576.

912 Snyder, R. E. 2006. Multiple risk reduction mechanisms: can dormancy substitute for dispersal? Ecology Letters 9:1106-1114.

914 Soininen, J. 2016. Spatial structure in ecological communities - a quantitative analysis. Oikos 125:160-166.

916 Starrfelt, J., and H. Kokko. 2012. Bet-hedging — a triple trade-off between means, variances and correlations. Biological Reviews 87:742-755.

918 Stevens, V. M., A. Trochet, H. Van Dyck, J. Clobert, and M. Baguette. 2012. How is dispersal integrated in life histories: a quantitative analysis using butterflies. Ecology Letters $920 \quad 15: 74-86$.

Sullivan, L. L., A. T. Clark, D. Tilman, and A. K. Shaw. 2018. Mechanistically derived dispersal 922 kernels explain species-level patterns of recruitment and succession. Ecology 99:24152420.

924 Tellier, A. 2019. Persistent seed banking as eco-evolutionary determinant of plant nucleotide diversity: novel population genetics insights. New Phytologist 221:725-730.

926 Templeton, A. R., and D. A. Levin. 1979. Evolutionary consequences of seed pools. The American Naturalist 114:232-232. 
928 Tilman, D. 1994. Competition and biodiversity in spatially structured habitats. Ecology 75:2-16.

Urban, M. C., and L. De Meester. 2009. Community monopolization: local adaptation enhances

930 priority effects in an evolving metacommunity. Proceedings of the Royal Society B: Biological Sciences 276:4129-4138.

932 Urban, M. C., M. A. Leibold, P. Amarasekare, L. De Meester, R. Gomulkiewicz, M. E. Hochberg, C. A. Klausmeier, et al. 2008. The evolutionary ecology of metacommunities. $934 \quad$ Trends in Ecology \& Evolution 23:311-317.

Urban, M. C., and D. K. Skelly. 2006. Evolving metacommunities: toward an evolutionary 936 perspective on metacommunities. Ecology 87:1616-1626.

Vandvik, V., and D. E. Goldberg. 2006. Sources of diversity in a grassland metacommunity: 938 quantifying the contribution of dispersal to species richness. The American Naturalist 168:157-167.

940 Vanoverbeke, J., M. C. Urban, and L. De Meester. 2016. Community assembly is a race between immigration and adaptation: eco-evolutionary interactions across spatial scales.

$942 \quad$ Ecography 39:858-870.

Vanschoenwinkel, B., S. Gielen, M. Seaman, and L. Brendonck. 2009. Wind mediated dispersal of freshwater invertebrates in a rock pool metacommunity: differences in dispersal capacities and modes. Hydrobiologia 635:363-372.

946 Vanschoenwinkel, B., A. Waterkeyn, M. Jocqué, L. Boven, M. Seaman, and L. Brendonck. 2010. Species sorting in space and time - the impact of disturbance regime on community assembly in a temporary pool metacommunity. Journal of the North American Benthological Society 29:1267-1278.

950 Vellend, M. 2016. The theory of ecological communities. Princeton University Press, Princeton, NJ. 
952 Venable, D. L., and J. S. Brown. 1988. The selective interactions of dispersal, dormancy, and seed size as adaptations for reducing risk in variable environments. The American

$954 \quad$ Naturalist 131:360-384.

Ventura, M., A. Petrusek, A. Miró, E. Hamrová, D. Buñay, L. De Meester, and J. Mergeay.

956 2014. Local and regional founder effects in lake zooplankton persist after thousands of years despite high dispersal potential. Molecular Ecology 23:1014-1027.

958 Verin, M., and A. Tellier. 2018. Host-parasite coevolution can promote the evolution of seed banking as a bet-hedging strategy. Evolution 72:1362-1372.

960 Viana, D. S., L. Santamaría, and J. Figuerola. 2016. Migratory birds as global dispersal vectors. Trends in ecology \& evolution 31:763-775.

962 Vitalis, R., S. Glémin, and I. Olivieri. 2004. When genes go to sleep: the population genetic consequences of seed dormancy and monocarpic perenniality. The American Naturalist $163: 295-311$.

Warner, R. R., and P. L. Chesson. 1985. Coexistence mediated by recruitment fluctuations: a field guide to the storage effect. The American Naturalist 125:769-787.

Waterkeyn, A., J. Vanoverbeke, N. Van Pottelbergh, and L. Brendonck. 2011. While they were sleeping: dormant egg predation by Triops. Journal of Plankton Research 33:1617-1621. 